\title{
Effect of Austenite Deformation on the Microstructure Evolution and Grain Refinement Under Accelerated Cooling Conditions
}

\author{
H. ZHAO and E.J. PALMIERE (D)
}

\begin{abstract}
Although there has been much research regarding the effect of austenite deformation on accelerated cooled microstructures in microalloyed steels, there is still a lack of accurate data on boundary densities and effective grain sizes. Previous results observed from optical micrographs are not accurate enough, because, for displacive transformation products, a substantial part of the boundaries have disorientation angles below $15 \mathrm{deg}$. Therefore, in this research, a niobium microalloyed steel was used and electron backscattering diffraction mappings were performed on all of the transformed microstructures to obtain accurate results on boundary densities and grain refinement. It was found that with strain rising from 0 to 0.5 , a transition from bainitic ferrite to acicular ferrite occurs and the effective grain size reduces from 5.7 to $3.1 \mu \mathrm{m}$. When further increasing strain from 0.5 to 0.7 , dynamic recrystallization was triggered and postdynamic softening occurred during the accelerated cooling, leading to an inhomogeneous and coarse transformed microstructure. In the entire strain range, the density changes of boundaries with different disorientation angles are distinct, due to different boundary formation mechanisms. Finally, the controversial influence of austenite deformation on effective grain size of low-temperature transformation products was argued to be related to the differences in transformation conditions and final microstructures.
\end{abstract}

DOI: $10.1007 / \mathrm{s} 11661-017-3987-\mathrm{z}$

(C) The Author(s) 2017. This article is an open access publication

\section{INTRODUCTION}

THE essence of thermomechanical processing is austenite deformation below the recrystallization-stop temperature $\left(T_{5 \mathrm{pct}}\right){ }^{[1]}$ After austenite deformation below the $T_{5 \text { pct }}$, several changes in austenite state are made, including grain shape, texture, density of substructures, annealing twin boundaries (changed into normal high-angle grain boundaries (HAGBs) during deformation), and bulging of austenite grain boundaries. ${ }^{[2]}$ This austenite conditioning strongly affects the transformed microstructure and, hence, the final mechanical properties. ${ }^{[3,4]}$

For thermomechanically processed microalloyed steels, air cooling often leads to a ferrite-pearlite microstructure with mechanical properties commonly below the X-70 grade. To further improve the properties, accelerated cooling (ACC) is necessary. Based on the understanding of the transformation behaviors of

H. ZHAO and E.J. PALMIERE are with the Department of Materials Science and Engineering, The University of Sheffield, Sir Robert Hadfield Building, Mappin Street, Sheffield S1 3JD, U.K. Contact e-mail: e.j.palmiere@sheffield.ac.uk

The original version of this article was revised: this article is now published open access per Springer Nature's compact agreement with the UK.

Manuscript submitted August 12, 2016.

Article published online May 1, 2017 deformed austenite during continuous cooling, the advantage of ACC on the improvement of both strength and toughness was studied during the $1970 \mathrm{~s} .{ }^{[5]}$ The wide application of online ACC equipment not only increases the productivity significantly in steel plate mills, ${ }^{[6]}$ but also brings good control of the transformed microstructures. ${ }^{[7]}$

For low-carbon microalloyed steels, ACC after finish rolling exploits the enhanced hardenability of these steels to produce low-temperature transformation products, mainly bainitic ferrite (BF) and acicular ferrite (AF), to improve strength. As classic bainite, $\mathrm{BF}$ grows in the form of clusters of parallel thin lenticular plates or laths, known as packets, but owing to the low-carbon concentration in the microalloyed steels, cementite is usually absent, yielding a well-organized microstructure consisting of $\mathrm{BF}$ and microconstituents, such as martensite and retained austenite (M/A). The formation of $\mathrm{M} /$ A constituents can be attributed to the partitioning of carbon from these BF laths to the surrounding austenite during cooling. Differently, AF was first introduced by Smith et al. ${ }^{[8]}$ in 1972. It was defined as being comprised of nonequiaxed ferrite laths with high-density substructures formed at relatively higher temperatures than bainite by a mixture of diffusion and displacive transformation mechanisms. Despite the unique morphology of AF, many investigations have shown that the 
transformation mechanism of $\mathrm{AF}$ is similar to that of $\mathrm{BF} .^{[8-13]}$

As for the grain refinement of low-temperature transformation products, although the effect of austenite deformation has been studied by many researchers, the results are still controversial. In a prior investigation, ${ }^{[14]}$ it was shown that the effective grain size of bainite increases from 3.2 to $3.8 \mu \mathrm{m}$ when austenite was deformed by 30 pct. Similarly, the block size of bainite was found to increase after austenite deformation, ${ }^{[15]}$ and the quantity of packets in each austenite grain also decreased after austenite deformation. ${ }^{[16]}$ More importantly, it was revealed from these investigations that even after significant amounts of austenite deformation, the transformation product still consists of parallel BF laths. Contradicting this were the prior research results ${ }^{[12,17,18]}$ in which the transformed microstructures mainly were nonequiaxed AF laths with an irregular arrangement and the transformed microstructure was refined after austenite deformation. However, it should be noted that in earlier research, ${ }^{[12,17,18]}$ the changes of grain refinement were observed directly from optical micrographs, which are not accurate enough, because for displacive transformation products, the boundaries revealed in the optical micrographs after etching are not necessarily HAGBs $(\theta>15 \mathrm{deg}$, where $\theta$ is the boundary disorientation angle) and a substantial part of the boundaries are low-angle grain boundaries (LAGB, $\theta \leq 15 \mathrm{deg})$. Therefore, crystallographic data obtained from electron backscattering diffraction (EBSD) mappings are indispensable to obtaining accurate results on the change of grain refinement for low-temperature transformation products ( $\mathrm{BF}$ and $\mathrm{AF}$ ).

In this research, a commercial high-temperature processing (HTP) concept steel is used to investigate the influence of austenite deformation below the recrystallization-stop temperature $\left(T_{5 \mathrm{pct}}\right)$ on the microstructure evolution under ACC conditions. More importantly, EBSD mappings are performed on all of the transformed microstructures to provide accurate results on the changes of boundary densities and grain refinement.

\section{EXPERIMENTAL}

The chemical composition of tested HTP steel is shown in Table I. To simulate the hot deformation processes during industrial plate production, plane strain compression (PSC) tests were adopted. Specimens with dimensions of $60 \mathrm{~mm} \times 30 \mathrm{~mm} \times 10 \mathrm{~mm}$ were machined from the received HTP steel pipe section. All the PSC tests were conducted using the servohydraulic thermomechanical compression (TMC) machine at The University of Sheffield. The operating system of the
TMC machine is fully digitized and computer controlled to allow a precise control of deformation parameters. During PSC tests, the specimen was deformed between two flat parallel tools (with a width of $15 \mathrm{~mm}$ at room temperature) and the temperature of the specimen was sampled through a thermocouple embedded into the PSC specimen.

In order to fully exploit the high $\mathrm{Nb}$ concentration in this steel, and to fully dissolve its precipitates and shorten the preheating time during PSC tests, all specimens were heated to $1523 \mathrm{~K}\left(1250{ }^{\circ} \mathrm{C}\right)$, held for 30 minutes with argon atmosphere protection, and water quenched to room temperature before PSC tests.

The typical $T_{5 \text { pct }}$ for HTP concept steels was estimated to be around $1323 \mathrm{~K}\left(1050{ }^{\circ} \mathrm{C}\right)$ in prior research. ${ }^{[19]}$ However, the true $T_{5 \mathrm{pct}}$ determined through multihit compression testing for such high $\mathrm{Nb}$ containing steels is not well documented. According to the double-hit compression test results obtained by Miao et al. with a high $\mathrm{Nb}$-bearing $(0.1 \mathrm{wt}$ pct) pipeline steel, ${ }^{[20]}$ after 25 pct austenite deformation, the percentage of recrystallization is below 10 pct after holding 500 seconds at $1253 \mathrm{~K}\left(980^{\circ} \mathrm{C}\right)$, only 40 pet after holding 500 seconds at $1273 \mathrm{~K}\left(1000^{\circ} \mathrm{C}\right)$, and 50 pet after holding 10 seconds at $1323 \mathrm{~K}\left(1050{ }^{\circ} \mathrm{C}\right)$. Based on these results, in this research, the roughing deformation temperature was selected as $1373 \mathrm{~K}\left(1100{ }^{\circ} \mathrm{C}\right)$ while the finishing deformation temperature was chosen as $1223 \mathrm{~K}\left(950^{\circ} \mathrm{C}\right)$. To confirm the validity of these temperatures, prior-austenite microstructures were also examined. The processing route is illustrated in Figure 1. The heat-treated specimens were reheated to $1473 \mathrm{~K}\left(1200{ }^{\circ} \mathrm{C}\right)$ at a rate of $10 \mathrm{~K} / \mathrm{s}$, held for 2 minutes for equilibration, and then cooled at a rate of $5 \mathrm{~K} / \mathrm{s}$ to $1373 \mathrm{~K}\left(1100{ }^{\circ} \mathrm{C}\right)$ for a roughing deformation (strain 1) of 0.3 at a constant true strain rate of $10 \mathrm{~s}^{-1}$.After that, the specimens were cooled immediately to $1223 \mathrm{~K}$ $\left(950^{\circ} \mathrm{C}\right.$ ) at a rate of $5^{\circ} \mathrm{C} / \mathrm{s}$ for the finishing deformation with strain 2 varying from 0 to 0.7 . This second deformation was also performed at a constant true strain rate of $10 \mathrm{~s}^{-1}$ and was followed by ACC from $1223 \mathrm{~K}$ to $773 \mathrm{~K}\left(950{ }^{\circ} \mathrm{C}\right.$ to $\left.500{ }^{\circ} \mathrm{C}\right)$ at a rate of $20 \mathrm{~K} / \mathrm{s}$, slow cooling from $773 \mathrm{~K}$ to $623 \mathrm{~K}\left(500{ }^{\circ} \mathrm{C}\right.$ to $\left.350{ }^{\circ} \mathrm{C}\right)$ at a rate of $1 \mathrm{~K} / \mathrm{s}$, and finally water quenching from $623 \mathrm{~K}$ $\left(350{ }^{\circ} \mathrm{C}\right)$ to room temperature. Furthermore, another three specimens were also heat treated and deformed but were water quenched directly before and after strain 2 of 0.5 and 0.7 to examine the as-deformed austenite microstructure.

Although, for the PSC tests on the TMC machine, specimens can be successfully deformed to the designed nominal strains, through a systematic thermomechanically coupled finite element (FE) analysis carried out by Mirza and Sellars, ${ }^{[21-23]}$ it was found that the equivalent strain distribution is not homogeneous in the deformed

Table I. Chemical Compositions (Weight Percent)

\begin{tabular}{lccccccccccc}
\hline $\mathrm{C}$ & $\mathrm{Mn}$ & $\mathrm{Si}$ & $\mathrm{S}$ & $\mathrm{P}$ & $\mathrm{Nb}$ & $\mathrm{Cr}$ & $\mathrm{Ni}$ & $\mathrm{Cu}$ & $\mathrm{Ti}$ & $\mathrm{N}$ \\
\hline 0.045 & 1.43 & 0.14 & $<0.003$ & $<0.01$ & 0.09 & 0.21 & 0.12 & 0.21 & 0.01 & 0.0039 \\
\hline
\end{tabular}


specimen. The inhomogeneity of strain distribution can cause nonuniform microstructures during subsequent continuous cooling. Therefore, to accurately investigate the microstructure evolution, the observation area must be selected carefully. According to the results shown in earlier research, ${ }^{[21]}$ with the same specimen and tool geometry as those in this research, the suitable area where the nominal strain is equal to the real equivalent strain actually is not located at the center along the rolling direction of the specimen, deviating 1 to $4 \mathrm{~mm}$ from it. Furthermore, due to the existence of intense friction on the specimen surface contacting with the tools during deformation, the strain conditions near these contacting surfaces will be far from plane strain conditions and the suitable area is located at the center along the normal direction. Therefore, the area at the center along the normal direction and deviating 1 to 4 $\mathrm{mm}$ from the center along the rolling direction was selected for all microstructure characterization in this research.

Specimens for metallographic observation were cut on the rolling direction-normal direction (RD-ND) plane and prepared carefully following standard methods. ${ }^{[24]}$ A 2 pet nital solution was used to show the transformed microstructures, and a saturated aqueous picric acid solution was used to reveal the prior-austenite grain boundaries (PAGBs). ${ }^{[25,26]}$

The EBSD mappings were carried out via a FEI Sirion electron microscope with an HKL Nordlys F + detector. EBSD mapping with a step size of $0.2 \mu \mathrm{m}$ and accelerating voltage of $20 \mathrm{kV}$ was performed on the RD-ND plane of each specimen. To reduce the misindexing of phases in these complex microstructures, $\alpha$ iron (bcc) was chosen as the only matching unit. Following a recommended method, ${ }^{[27]}$ noise points of raw data were removed and nonindexed points were filled with the common orientation of their neighbors using HKL Channel 5 Tango software.

Besides microscopy, mechanical properties of the transformed products were characterized by Vickers microhardness with a 500-g applied load and 20-seconds dwelling time on a Mitutoyo hardness testing machine. Ten indentations were measured from each specimen.

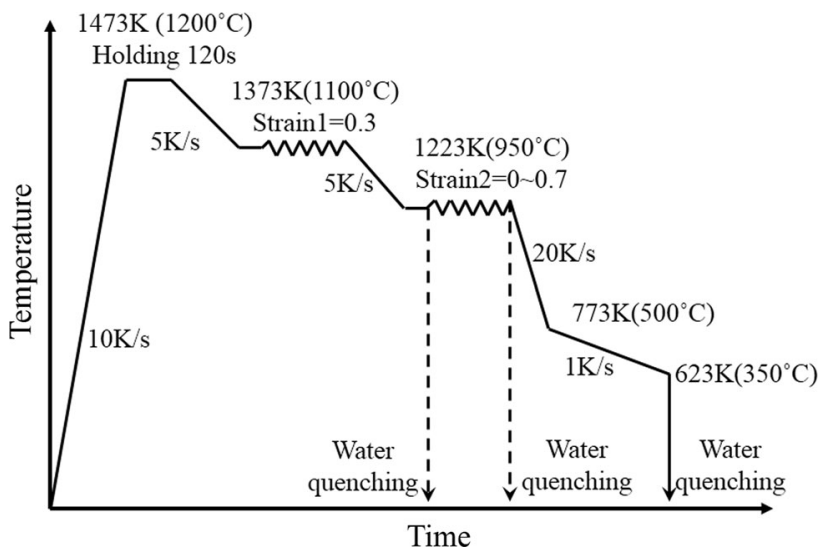

Fig. 1-Schematic illustration of the thermomechanical testing profile.

\section{RESULTS}

\section{A. Deformation Process}

The load-displacement data recorded during the austenite deformation was converted into the von Mises equivalent stress-strain data according to a standard procedure. ${ }^{[28]}$ The flow stress curve with strain 2 of 0.7 is shown in Figure 2. It can be seen that during the second deformation, the flow stress increased gradually with strain 2 and started to decrease after reaching a peak strain, which is a characteristic of dynamic recrystallization (DRX). Under low temperatures and high strain rates, namely, high $Z$ conditions, the peak of the DRX curve may become very broad, which makes it similar to the dynamic recovery only curves. Under this situation, a plot of the derivative of the stress to strain vs. stress can be used to reveal the subtle DRX peak, ${ }^{[29]}$ as shown in Figure 2(b). The peak stress can be identified as 204.1 $\mathrm{MPa}$ when the derivative is equal to 0 ; thus, the peak strain can be identified as strain 2 of 0.56 . However, this flow stress curve only reflects the average, macroscopic deformation condition of the entire specimen. Due to

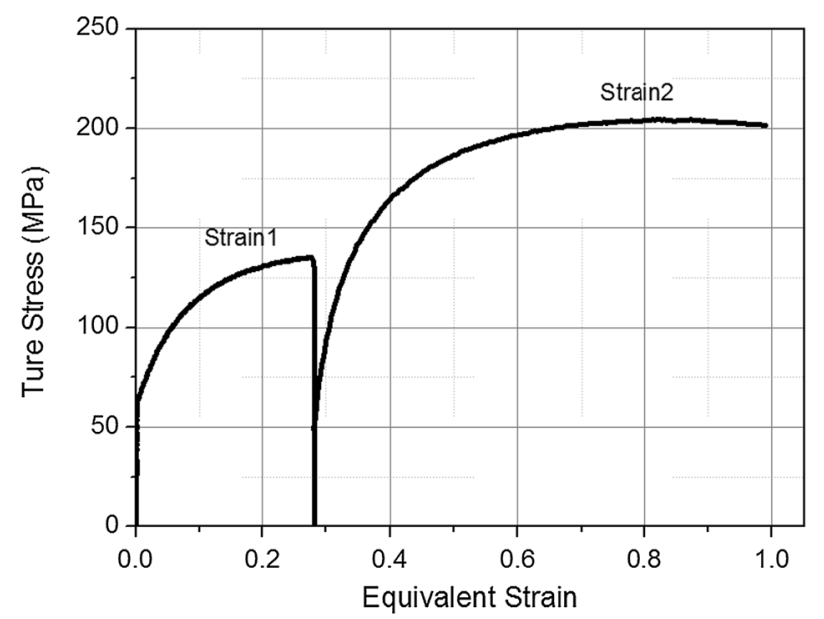

(a)

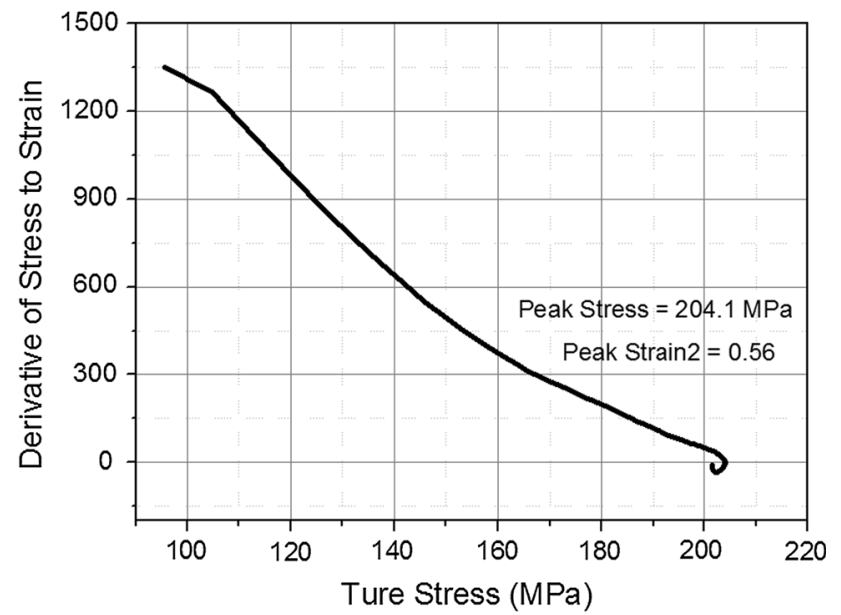

(b)

Fig. 2-(a) Macroscopic flow behavior from the testing scheme of strain 2 of 0.7 . (b) Plot of the derivative of stress to strain vs. the true stress for strain 2 of 0.7 . 
the existence of strain gradients in the current PSC tests, ${ }^{[21-23]}$ optical micrographs depicting the PAGBs before and after strain 2 of 0.5 and 0.7 are shown in Figure 3, to determine the austenite deformation behavior accurately.

In Figure 3(a), it is evident that before strain 2, austenite grains are fully recrystallized with an average linear intercept length of $37 \mu \mathrm{m}$ measured from multiple micrographs. In Figure 3(b), austenite microstructure remains in an uncrystallized condition, while in Figure 3(c), there are some small dynamically recrystallized grains at the triple junctions of the elongated austenite grains. The recrystallization fraction was measured as 6 pct, which means that at strain 2 of 0.7 , DRX was just triggered during austenite deformation, and the recrystallization fraction is quite low at the end of deformation.

\section{B. Transformed Microstructures}

To observe the microstructure evolution with the increase of strain 2, scanning electron microscopy (SEM) secondary electron micrographs of the transformed microstructure are shown in Figures 4(a) through (e). In Figures 4(a) and (b), a parallel morphology of the transformation products can be seen clearly. The PAGBs remain, and the parallel laths developed from the PAGBs extend into the austenite grain, sometimes across the whole grain, which is a typical BF morphology. From Figures 4(c) and (d), with the increased strain 2, the microstructure becomes finer and the parallel BF laths get shorter. The fraction of parallel BF laths is gradually reduced and the rest are nonequiaxed ferrite laths with a chaotic arrangement, which can be classified as AF. This indicates that with the increase of austenite deformation, a transition from $\mathrm{BF}$ to AF occurs, consistent with previous research. ${ }^{[12,17,18]}$ Finally, in Figure 4(e), despite the further increased strain 2, the fraction of AF is not increased and the microstructure becomes inhomogeneous with coarse BF packets surrounding fine AF laths.

Throughout all the preceding micrographs, M/A constituents appearing white can be found distributing within the matrix. It is clear in Figures 4(a) through (d) that the shape of $\mathrm{M} / \mathrm{A}$ constituents changes from elongated rods to dispersed, equiaxed particles with the increase of strain 2 from 0 to 0.5 . This shape change can be related to the transition from BF to AF. When the transformation product mainly is $\mathrm{BF}$, which is a highly organized microstructure with packets of parallel laths with similar crystallographic orientations, ${ }^{[4]}$ the remaining austenite largely exists between $\mathrm{BF}$ laths, leading to the coarse, elongated rod shape of $\mathrm{M} / \mathrm{A}$ constituents. In contrast, when the transformation product is AF dormant, which exhibits a relatively chaotic microstructure, ${ }^{[9]}$ the remaining austenite largely locates between AF laths with different shapes and directions, resulting in the fine, equiaxed shape of $M / A$ constituents. This morphology change of $\mathrm{M} / \mathrm{A}$ constituents was also observed in another investigation. ${ }^{[30]}$ The existence of coarse $\mathrm{M} / \mathrm{A}$ constituents normally causes a detrimental effect on toughness; ${ }^{[31,32]}$ therefore, the refinement of $\mathrm{M} / \mathrm{A}$ constituents through austenite deformation can alleviate the negative effect of $\mathrm{M} / \mathrm{A}$ constituents on toughness.

\section{EBSD Mapping}

Following the noise reduction, a small area of each EBSD data set was used to plot a boundary map. For a statistical analysis of the boundary density distribution and boundary interception length, each whole data set was used.

The selected area boundary maps are shown in Figure 5. From Figures 5(a) through (d), although BF microstructures revealed by parallel LAGBs can be seen clearly in all figures, the length and fraction of parallel $\mathrm{BF}$ laths reduce gradually with the increased austenite deformation. Additionally, the $\mathrm{BF}$ microstructure is replaced by nonequiaxed AF laths with a chaotic arrangement, indicating a transition from $\mathrm{BF}$ to $\mathrm{AF}$ as austenite deformation is increased. Together with these morphological changes, the densities of both HAGBs and LAGBs significantly increase. However, further increasing strain 2 from 0.5 to 0.7 , the densities of both HAGBs and LAGBs are reduced, as shown in Figures 5(d) and (e). The characteristics of microstructure evolution observed in the boundary maps correspond well to those obtained from SEM micrographs. Moreover, due to the advantages of EBSD mapping, these microstructure changes can be quantified accurately.

Based on the EBSD maps covering relatively large areas of the tested specimens, the boundary densities in terms of absolute number per unit area are plotted against the disorientation angles as distribution histograms in Figure 6, to reveal the boundary characteristics of the transformed microstructures. The whole disorientation angle scope can be divided into four ranges, range $1(\theta<10 \mathrm{deg})$, range $2(10 \mathrm{deg} \leq \theta<21$ $\mathrm{deg}$ ), range 3 (21 deg $\leq \theta<47 \mathrm{deg}$ ), and range 4 (47 deg $\leq \theta \leq 62.8 \mathrm{deg}$ ), due to different formation mechanisms.

The displacive transformation characteristic of the transformed microstructures can be seen directly from the boundary density distributions shown in Figure 6. For all transformed microstructures, the densities (frequencies) of boundaries with disorientation angles in range 3 are very low. This is because both $\mathrm{AF}$ and $\mathrm{BF}$ are displacive transformation products, following a near Kurdjumov-Sachs (K-S) or Nishiyama-Wasserman $(\mathrm{N}-\mathrm{W})$ orientation relationship with parent austenite grains. ${ }^{[3,33]}$ For the $\mathrm{K}-\mathrm{S}$ or $\mathrm{N}-\mathrm{W}$ orientation relationships, the disorientation angles of boundaries between different laths transformed in the same parent austenite grain do not fall into range 3 between 21 and 47 deg. ${ }^{[34]}$ The boundaries with disorientation angles within range 3 shown in Figure 6 are the boundaries between laths transformed from different austenite grains at PAGBs, but not vice versa. Since the area of PAGBs only accounts for a small portion of the total boundary area of the transformed microstructure and it increases with austenite deformation, the boundary densities in range 3 (21 to $47 \mathrm{deg}$ ) are considerably lower than others and increase with the rise of strain 2. Based on these results, the characteristics of boundary density distributions 

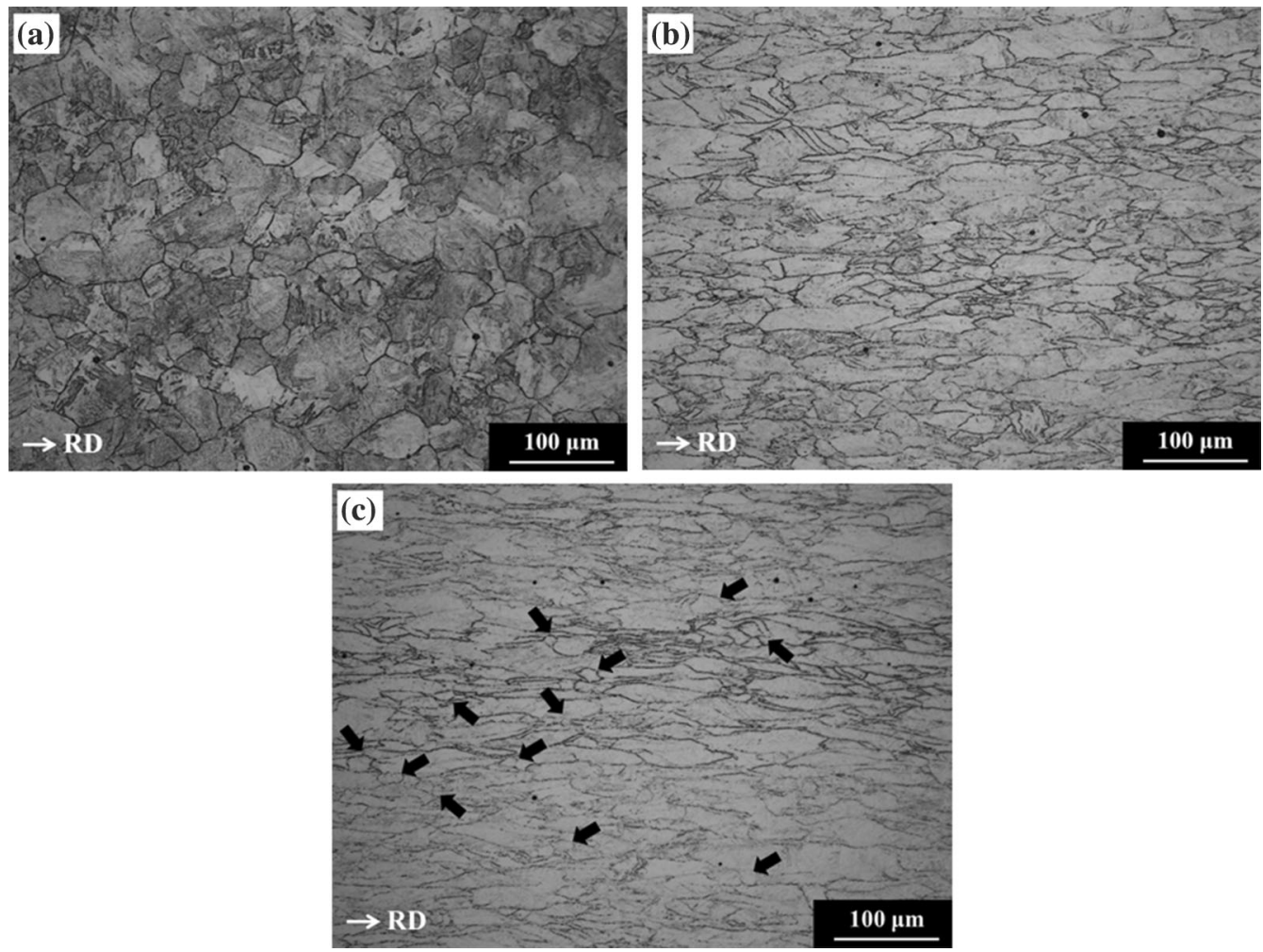

Fig. 3 - Optical micrographs showing PAGBs of water-quenched specimens: $(a)$ after strain 1 of $0.3,(b)$ after strain 2 of 0.5 , and (c) after strain 2 of 0.7 . DRX grains are marked by black arrows.

shown in Figure 6 add evidence that the transformation mechanisms of $\mathrm{AF}$ and $\mathrm{BF}$ are similar and displacive.

It can also be seen in Figure 6 that the boundary densities (frequencies) of all EBSD data sets in other disorientation angle ranges, 1,2 , and 4 , increase with the rise of strain 2 from 0 to 0.5 and fall at strain 2 of 0.7 . The reason for that is explained in Section IV-C.

The increase in the HAGB density results in a refined microstructure. To quantify the microstructure refinement, disorientation angle threshold values should be selected. Different disorientation angle threshold values have been used to define microstructure parameters that can be related to certain mechanical properties, and the microstructural unit size that controls strength may differ from that which controls toughness. Disorientation angles of 4 and $15 \mathrm{deg}$ are typical threshold values to define the microstructural unit sizes responsible for strengthening and toughening, respectively. ${ }^{[3,36]}$ Low disorientation angle (4 deg) grain size is one of the factors that controls the yield and tensile strength of steels, because boundaries with disorientation angles above this value are expected to oppose dislocation movements, while HAGBs $(\theta>15 \mathrm{deg})$ provide effective barriers to cleavage fractures. ${ }^{[35,37]}$

The grain size defined by different disorientation threshold values, 4 and $15 \mathrm{deg}$, was measured by a linear intercept method in the Channel 5 software. The geometric means of linear intercept lengths in both the horizontal and vertical directions were calculated as in Reference 27 and are shown in Figure 7.
It can be seen that the mean linear intercept lengths following both disorientation threshold values decrease with the rise of strain 2 from 0 to 0.5 , but they increase as strain 2 changes from 0.5 to 0.7 . Furthermore, the difference among all the specimens is statistically significant, as there is very limited overlapping of their $95 \mathrm{pct}$ CL error bars. The adjacent laths with disorientation below 15 deg make up the effective grains. ${ }^{[12]}$ Since the effective grain boundaries $(\theta \geq 15 \mathrm{deg})$ act as obstacles to cleavage crack propagation, the reduction of effective grain size can result in better toughness, especially in terms of the ductile-brittle transition temperature. ${ }^{[12]}$

\section{Hardness Tests}

The microhardness values of the transformed microstructures vs. the amount of strain 2 are shown in Figure 8. Hardness rises slightly with the increase of strain 2 but decreases when strain 2 reaches 0.7 . This microhardness changing behavior corresponds well to that of the linear interception lengths with a threshold value of 4 deg.

\section{DISCUSSION}

\section{A. Austenite Restoration Before Phase Transformation}

It is evident from the research results in Section III that the microstructure refining and strengthening effect of austenite deformation is weakened when strain 2 reaches 0.7. Despite the onset of DRX during strain 2 of 

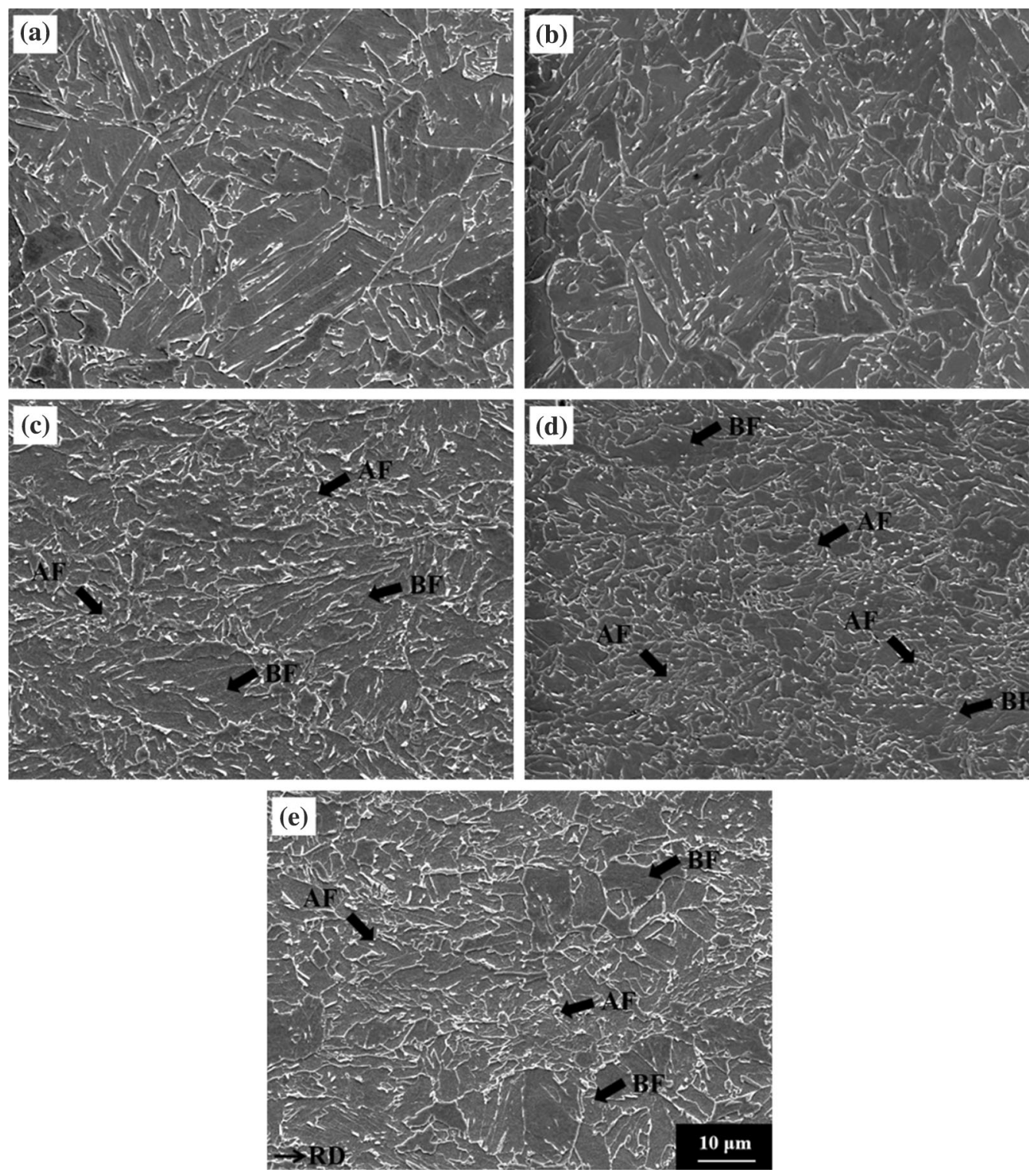

Fig. 4 - SEM secondary electron micrographs depicting the transformed microstructures after different strain 2 values: (a) $0,(b) 0.1,(c) 0.3,(d)$ 0.5 , and $(e) 0.7$.

0.7 , the fraction of austenite DRX is only 6 pct at the end of deformation, which is quite small compared to the hardness drop and microstructure coarsening shown in Figures 8 and 7, respectively. In Figure 8, the hardness result after strain 2 of 0.7 is at a slightly higher level than that after strain 2 of 0.3 , which indicates an austenite restoration fraction around 45 pet.

Since austenite deformation can increase the transformation start temperature of high-strength low-alloy steels during continuous cooling, it is reasonable to assume that $\mathrm{PF} / \mathrm{QF}$ could form after strain 2 of 0.7 in this research, leading to the drop in microhardness. However, according to the boundary misorientation angle distribution results of $\mathrm{PF} / \mathrm{QF}$ grains transformed both from recrystallized austenite and deformed austenite in research, ${ }^{[38]} \mathrm{PF} / \mathrm{QF}$ grain boundaries have high densities or frequencies in range 3 (21 deg $\leq \theta<47 \mathrm{deg}$ ). From the boundary density histograms shown in Figure 6, there is only a slight increase of boundary densities in range 3 as strain 2 rises from 0.5 to 0.7 , indicating no great increase of $\mathrm{PF} / \mathrm{QF}$ fractions. Therefore, there should be another restoration mechanism occurring after austenite deformation but before the subsequent phase transformation.

Under the cooling condition used in this research, displacive transformations dominate, as proven by the boundary density distribution histograms shown in Figure 6; therefore, PAGBs before phase transformation can also be revealed by etching with a saturated aqueous picric acid solution similar to that used for water-quenched specimens. The optical micrographs depicting the PAGBs before phase transformation after strain 2 of 0.5 and 0.7 are shown in Figures 9(a) and (b), 

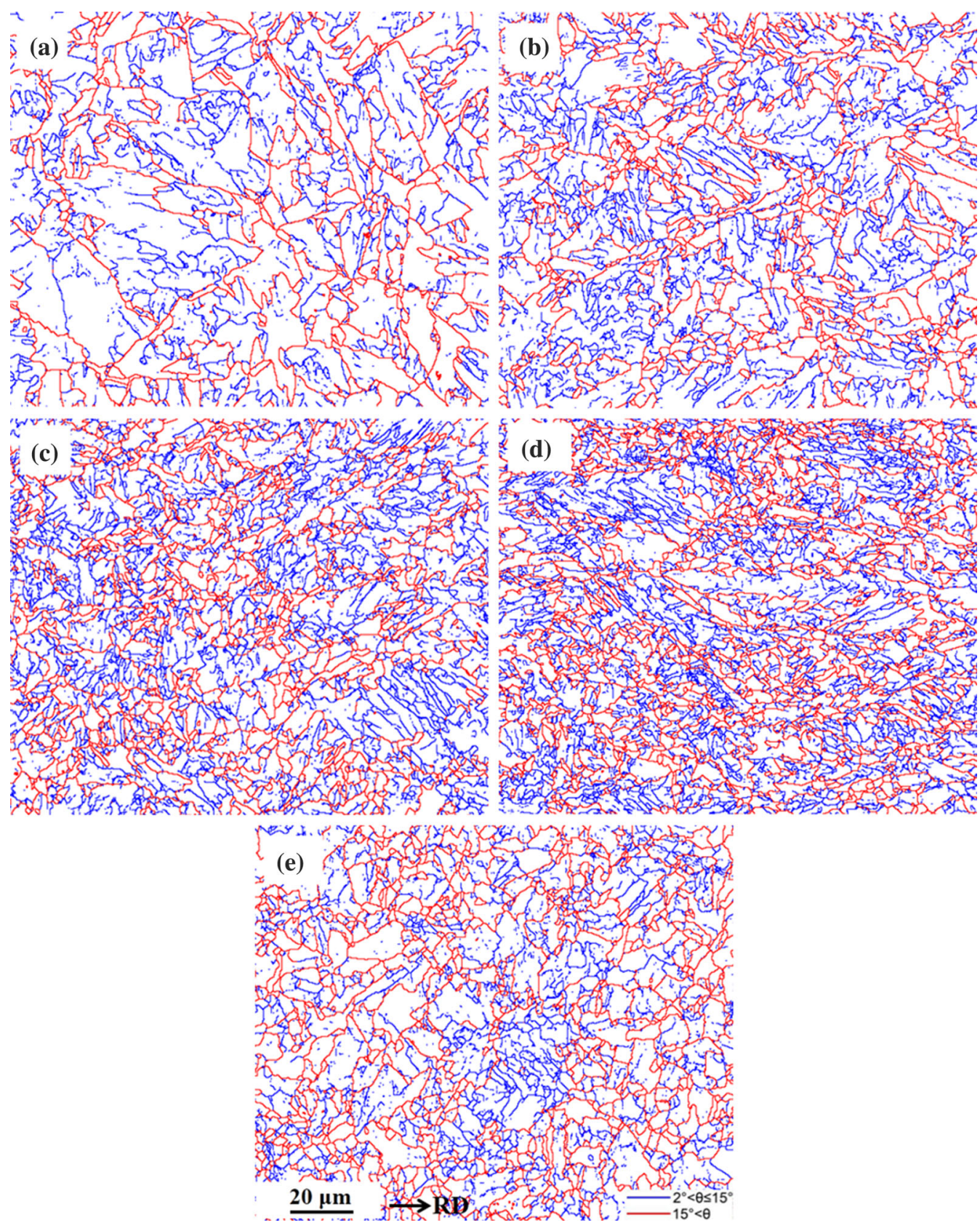

Fig. 5-EBSD boundary maps of transformed microstructures after strain 2 of $(a) 0,(b) 0.1,(c) 0.3,(d) 0.5$, and $(e) 0.7$, where blue lines represent low-angle boundaries with disorientation between 2 and $15 \mathrm{deg}$, while red lines represent high-angle boundaries with disorientation greater than $15 \mathrm{deg}$.

respectively. In Figure 9(a), after strain 2 of 0.5 and after continuous cooling, the prior-austenite still remains deformed, which suggests that with strain 2 of 0.5 , deformation temperature of $1223 \mathrm{~K}\left(950^{\circ} \mathrm{C}\right)$, and strain rate of $10 \mathrm{~s}^{-1}$, strain can be successfully accumulated in the austenite. It can be seen clearly in Figure 9(b) that many small equiaxed grains exist among uncrystallized, elongated austenite grains. The fraction of those small equiaxed grains was measured at 38.5 pct, which is very close to the restoration fraction indicated by the microhardness measurements. Since DRX was triggered with strain 2 of 0.7 and the deformation temperature is relatively high, $1223 \mathrm{~K}$ $\left(950{ }^{\circ} \mathrm{C}\right)$, a relatively long time gap, was left for the postdynamic softening to proceed.

As for the specific postdynamic softening mechanism, some researchers used to assume that static recrystallization (SRX) is the dominant softening mechanism when deformation strain is lower than the critical strain of DRX $\left(\varepsilon_{\mathrm{c}}\right)$. As long as the deformation strain is higher than $\varepsilon_{\mathrm{c}}$, the postdynamic softening is governed by the metadynamic recrystallization (MDRX) mechanism, which only involves the growth of previously nucleated DRX grains. ${ }^{[39]}$ However, when the fraction of DRX is 


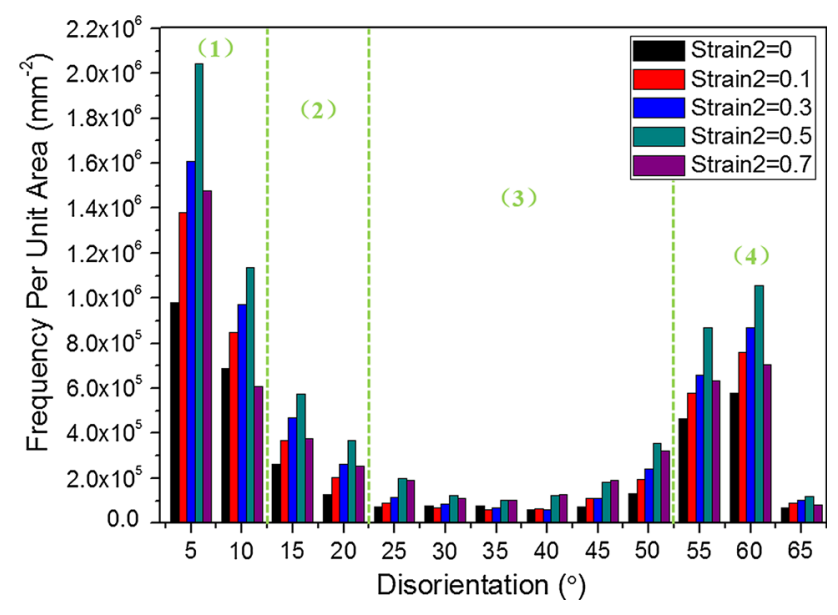

Fig. 6-Histograms showing the boundary densities in terms of absolute number per unit area with different disorientation angles from 2 to $62.8 \mathrm{deg}$.

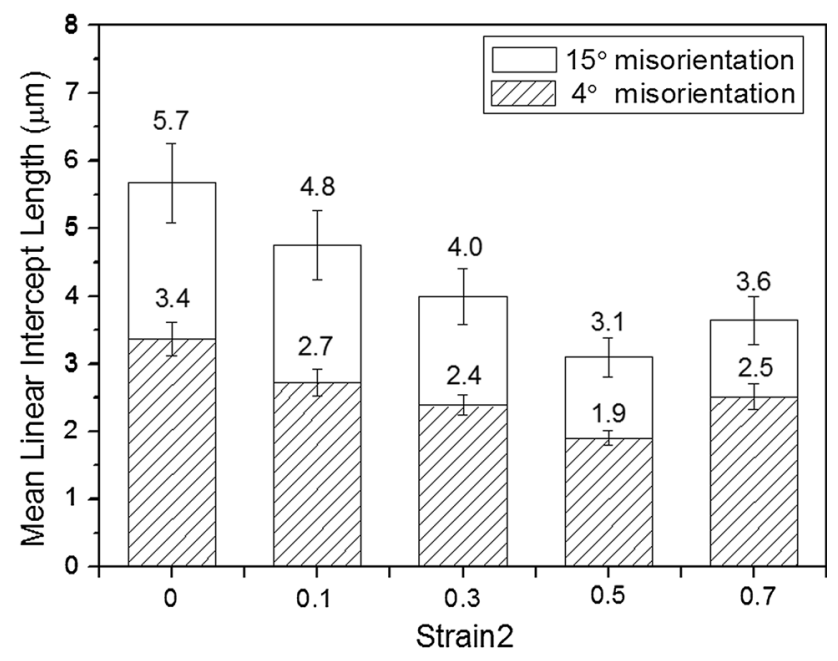

Fig. 7-Microstructure size parameter as the geometric mean of the linear interception lengths in horizontal and vertical directions from the EBSD maps measured against two disorientation criteria, 4 and 15 deg. The error bar represents the 95 pct confidence levels of the measurement.

low, MDRX cannot be accounted for by a high postdynamic softening fraction, and in a previous study, ${ }^{[40]}$ MDRX only became dominant after a minimum strain $\varepsilon_{\mathrm{T}}$ was reached. This strain $\varepsilon_{\mathrm{T}}$ is smaller than the steady-state strain $\varepsilon_{\mathrm{ss}}$ but can be significantly larger than $\varepsilon_{\mathrm{c}}$. The value of $\varepsilon_{\mathrm{T}}$ has been determined experimentally, ${ }^{[40]}$ leading to a relationship of $\varepsilon_{\mathrm{T}}=K \varepsilon_{\mathrm{p}}$, where $\varepsilon_{\mathrm{p}}$ is the peak strain with a constant $K$ of 1.7 . Therefore, a transition between the strain range was proposed, ${ }^{[40]}$ where SRX operates as the main postdynamic softening mechanism $\left(\varepsilon<\varepsilon_{\mathrm{c}}\right)$ and where MDRX takes over $\left(\varepsilon>\varepsilon_{\mathrm{T}}\right)$. In the interval between $\varepsilon_{\mathrm{c}}$ and $\varepsilon_{\mathrm{T}}$, both mechanisms contribute concurrently to the postdynamic softening. Based on the information provided previously, after strain 2 of 0.7 , both SRX and MDRX contributed to the softening and resulted in the hardness drop and microstructure coarsening when strain 2 reaches 0.7 .
Moreover, it is worth noticing that in Figure 4(e), a transformation microstructure consisting of fine AF laths surrounded by coarse, blocky $\mathrm{BF}$ packets is evident. The formation of this inhomogeneous microstructure can be attributed to the partially recrystallized austenite grains, as shown in Figure 9(b). The remaining unrecrystallized austenite transforms into $\mathrm{AF}$, while the recrystallized austenite grains change into $\mathrm{BF}$ packets, due to a lack of intragranular nucleation sites.

Based on the results shown previously, the occurrence of SRX/MDRX during ACC is hard to notice unless specimens with different strains are compared or the continuously cooled specimens are etched to reveal PAGBs. Moreover, the strain volume and deformation temperature of finish rolling should be selected carefully, especially for HTP steel, to minimize restoration processes, such as MDRX and SRX, from occurring prior to the phase transformation during ACC.

\section{B. Transition from BF to $A F$}

Despite the similarity in the transformation mechanisms, AF has a different morphology compared with that of BF. The formation of AF can be explained by the effect of deformation on introducing intragranular nucleation sites. It has been shown that the nucleation of bainite is related to the spontaneous dissociation of specific dislocation defects that are already present in the parent austenite. ${ }^{[4]}$ This is similar to martensite except for the requirement of carbon partitioning during the bainite nucleation stage. ${ }^{[41]}$ The embryo may be densely stacked dislocation arrays, ${ }^{[42]}$ and it has been suggested that the embryo requires a critical number of dislocations inside to be sufficiently potent. ${ }^{[43]}$ Therefore, in the undeformed or slightly deformed austenite, BF nucleates primarily on the austenite grain boundaries where densely stacked dislocations can be accommodated. When the austenite is heavily deformed, a high density of dislocations will be introduced into the austenite, which can increase the potent nucleation site densities for AF. Actually, the nucleation of AF has been observed on many deformation defects, such as deformation bands $\left.{ }^{[18,44} 46\right]$ and dislocation cell walls. ${ }^{[47]}$

\section{Effect of Austenite Deformation on Boundary Densities}

The change of boundary densities in the disorientation angle range 3 with increased strain 2 from 0 to 0.7 was explained in Section III-C. Differently, it can be seen in Figure 6 that the boundary densities (frequencies) in the disorientation angle ranges, 1, 2, and 4, increase with the rise of strain 2 from 0 to 0.5 and fall at strain 2 of 0.7 . A common reason is that with the increase of strain 2 from 0 to 0.5 , the fraction of AF is raised and both the $\mathrm{BF}$ and $\mathrm{AF}$ laths become increasingly small and short (Figure 4), leading to increased lath boundary densities. However, due to the formation of coarse BF packets from the recrystallized austenite grains with strain 2 of 0.7 , lath boundary density drops. Besides that, the reasons for the change of boundary 


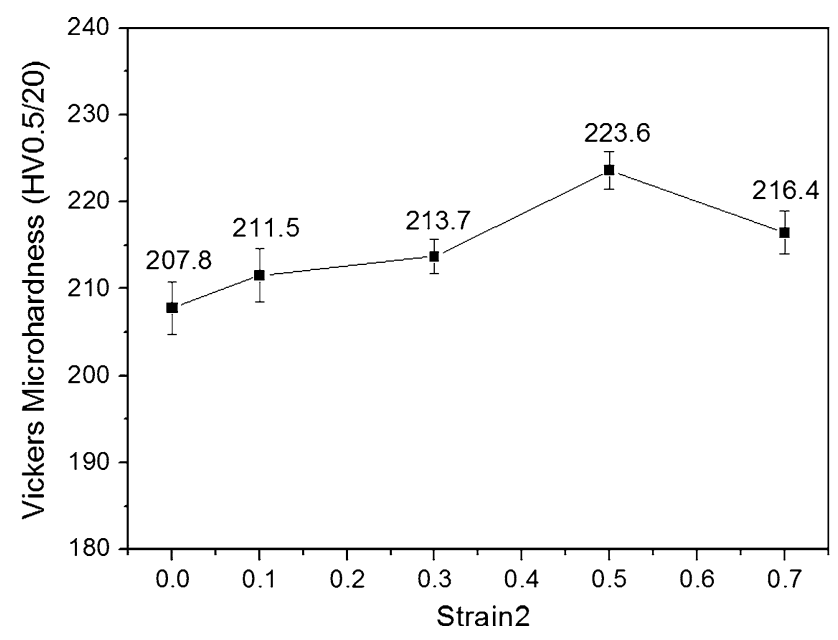

Fig. 8-Vickers microhardness of the transformation products after various deformation strains. The error bar represents the 95 pct confidence interval of the measurement.
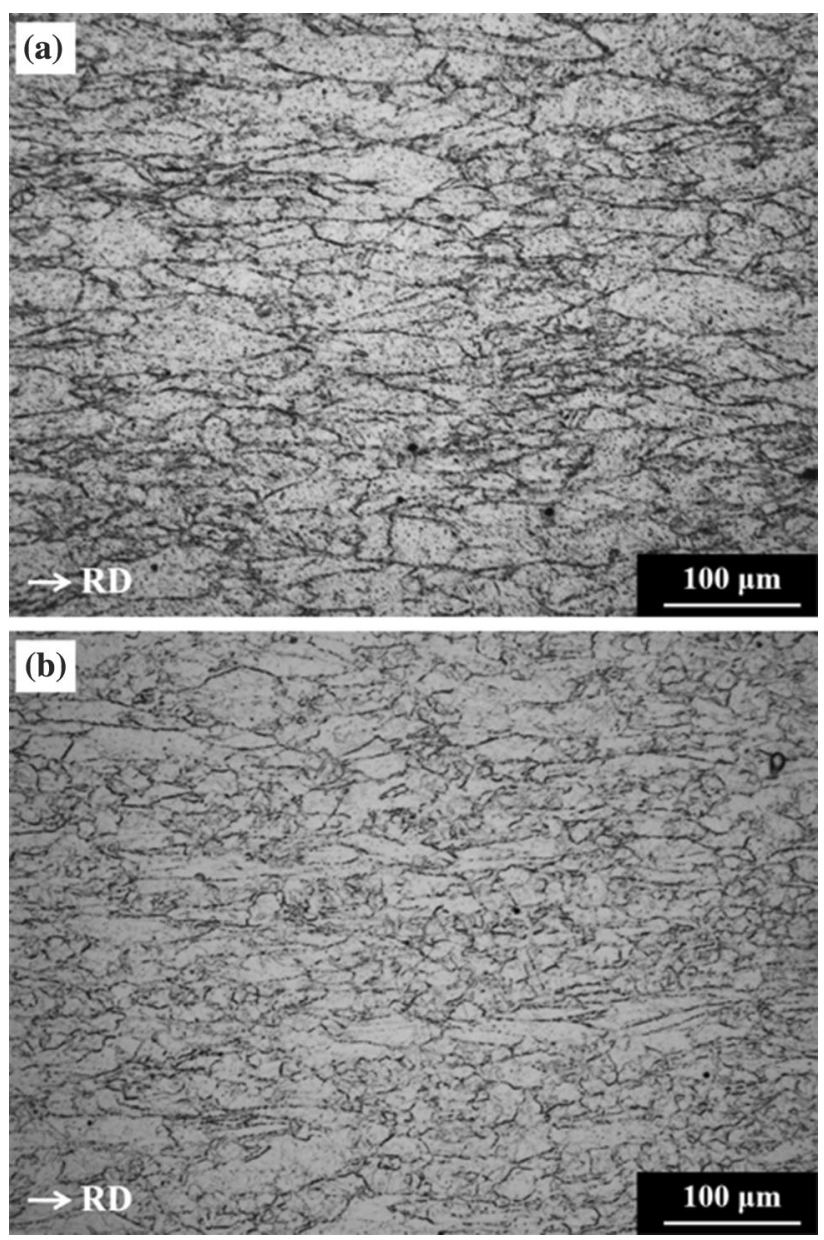

Fig. 9- Optical micrographs depicting PAGBs of continuous cooled specimens after strain 2 of $(a) 0.5$ and $(b) 0.7$.

densities in each disorientation angle range are slightly different.

Boundaries with disorientation angles in range 1 $(\theta<10 \mathrm{deg})$ mainly result from the plastic strains of austenite and $\mathrm{AF} / \mathrm{BF}$ to accommodate the displacive transformation shape strain. ${ }^{[48,49]}$ The main phase components in all transformed microstructures in this research, $\mathrm{AF}$ and $\mathrm{BF}$, both are displacive transformation products and, thus, have similar transformation shape strains. ${ }^{[4]}$ Given that, the boundary densities in range 1 should be close. However, since the main characteristic of displacive transformations is the coordinated movement of lattice atoms, ${ }^{[4]}$ austenite substructures introduced by deformation will be inherited by displacive transformation products. Therefore, the increase of strain 2 will generate more deformation substructures inherited by the displacive transformation products and finally lead to the increased boundary density in range 1 . The occurrence of SRX/MDRX after strain 2 of 0.7 lowers the deformation substructure density and results in the decrease of boundary densities in range 1.

Boundaries with disorientation angles in range 4 (47 deg $\leq \theta<62.8 \mathrm{deg}$ ) are mainly the boundaries between laths transformed in the same austenite grain but belonging to different Bain groups. ${ }^{[34]}$ The rise of boundary densities in range 3 as strain 2 increases from 0 to 0.5 can be mainly attributed to the formation of intragranular nucleated AF. During bainite transformation, strong variant selection occurs and results in the existence of certain variant pairs in the transformation product, thus leading to large boundary densities with certain disorientation angles. ${ }^{[50]}$ Under relatively slow cooling rates or high transformation temperatures, variant selection will mainly favor the variant pairs with low disorientation angles between them. ${ }^{[50]}$ However, for the AF dominant microstructures, austenite deformation increases the intragranular nucleation sites; therefore, more laths nucleate directly at intragranular nucleation sites instead of sympathetically nucleating in the form of variant pairs. The formation of these intragranularly nucleated laths can weaken the variant selection mechanisms; thus, more types of variants and variant pairs can be generated in each austenite grain. ${ }^{[11]}$ Therefore, the boundary densities in range 3 will increase with the rise of $\mathrm{AF}$ fraction as strain 2 changes from 0 to 0.5 . The occurrence of SRX/MDRX after strain 2 of 0.7 eliminates some of the intragranular nucleation sites, leading to the reduced $\mathrm{AF}$ fraction and, thus, the decreased boundary density in range 3 .

Boundaries with disorientation angles in range $2(10$ deg $\leq \theta<21 \mathrm{deg}$ ) are mainly the boundaries between laths transformed in the same austenite grain and belonging to the same Bain group. ${ }^{[34]}$ The change of boundary density in this range can be explained mainly by the change of lath boundary density, as illustrated in the beginning of this section.

It is also worth noticing that besides the disorientation angle range 3 , the disorientation angles of boundaries formed between laths transformed from different austenite grains can also fall into other disorientation angle ranges. However, since the area of PAGBs only accounts for a small portion of the total boundary area of the transformed microstructure, the influences of PAGBs are very small in ranges 1, 2, and 4 . 


\section{Controversial Effect of Austenite Deformation on Effective Grain Size}

As for the controversial influence of austenite deformation on the effective grain size of low-temperature transformation products, in this research, it can be seen clearly that the effective grain size decreases with the rise of accumulated strain in the austenite. This is consistent with other previous research results, ${ }^{[12,17,18]}$ although in that research, the changes of grain refinement were observed from optical micrographs. However, the result of this research differs from previous studies, ${ }^{[14-16]}$ which indicate that a coarser transformed microstructure forms after austenite deformation. There may be two different reasons for this. First, as in the case of strain 2 of 0.7 , DRX is triggered and SRX/MDRX occurs before the phase transformations. Therefore, despite the increase of austenite deformation from 0.5 to 0.7 , the microstructure begins to coarsen. However, this situation only happens when the deformation temperature is high and the cooling rate is relatively low.

The second and more likely reason can be attributed to the microstructure difference between these investigations. In the previous investigations, ${ }^{[12,17,18]} \mathrm{AF}$ microstructure is the main phase constituent after relatively slow continuous cooling, $30^{[12]}$ and $10 \mathrm{~K} /$ $\mathrm{s},{ }^{[17,18]}$ or isothermal holding at high temperatures, $773 \mathrm{~K}$ to $873 \mathrm{~K}\left(500{ }^{\circ} \mathrm{C}\right.$ to $\left.600{ }^{\circ} \mathrm{C}\right),{ }^{[12]}$ while in others, ${ }^{[14-16]}$ with relatively high cooling rates, $50 \mathrm{~K} /$ $\mathrm{s},{ }^{[14]}$ and low transformation temperatures, $623 \mathrm{~K}^{[15]}$ and $673 \mathrm{~K}\left(350^{\circ} \mathrm{C}\right.$ and $\left.400{ }^{\circ} \mathrm{C}\right),{ }^{[16]} \mathrm{BF}$ still dominates the transformed microstructure after austenite deformation.

The large amount of active intragranular nucleation sites resulted from the accumulated strain in austenite promoting the formation of $\mathrm{AF}$ and, thus, weakening the variant selection during displacive transformation, leading to smaller effective grain sizes. In contrast, at relatively low transformation temperatures, the intragranular nucleation sites become inactive and the final microstructure is still BF dormant even after significant amounts of austenite deformation. The reason why the intragranular nucleation sites become inactive under this condition is still unclear. For BF transformation, the main nucleation sites are austenite grain boundaries, and austenite deformation can only result in a very limited increase of austenite grain boundary area. Even worse, for $\mathrm{BF}$ transformation, austenite deformation can result in a strong variant selection that the habit planes of BF laths correspond to the active slip planes in austenite during deformation, which finally leads to larger effective grain sizes. ${ }^{[52]}$ This difference can be noted in another investigation. ${ }^{[53]}$ In that study, a wide cooling rate range $(0.1$ to $100 \mathrm{~K} / \mathrm{s})$ was used, and under low to medium cooling rates $(0.1$ to $20 \mathrm{~K} / \mathrm{s})$, the austenite deformation has a beneficial effect on the effective grain size reduction for ferrite-pearlite microstructures and AF-like microstructures, which can be attributed to the increased intragranular nucleation sites. However, in the high cooling rate range (20 to $100 \mathrm{~K} / \mathrm{s}$ ), the beneficial microstructure refining effect of austenite deformation completely disappears, and the increase of effective grain size occurs when BF becomes the dominant phase. Therefore, the controversial influence of austenite deformation on the effective grain size of low-temperature transformation products can be related to the differences in transformation conditions and final microstructures.

\section{CONCLUSIONS}

In this research, the effect of austenite deformation on the microstructure evolution and grain refinement of a niobium microalloyed steel subjected to PSC and ACC was investigated. The following conclusions can be drawn.

1. With the increase of strain from 0 to 0.5 , a transition from $\mathrm{BF}$ to $\mathrm{AF}$ occurs, owing to the introduction of intragranular nucleation sites, and the microhardness and the overall grain boundary density increase with the rise of AF fraction in the transformed microstructure.

2. Increasing strain further from 0.5 to 0.7 leads to a reduced microhardness and an inhomogeneous transformation microstructure with fine $\mathrm{AF}$ laths surrounded by coarse, blocky BF packets. This can be attributed to the occurrence of DRX and subsequent postdynamic softening with strain of 0.7 , which leads to a partially recrystallized austenite and a drop of accumulated strain in austenite.

3. The displacive transformation characteristic of $\mathrm{BF}$ and AF can be seen directly from the significantly lower boundary densities with disorientation angles between 21 and $47 \mathrm{deg}$. Due to the differences in the formation mechanisms of boundaries with various disorientation angles, the changes of boundary densities in different disorientation angle ranges with the increase of strain 2 are not the same.

4. The effective grain size measured accurately from EBSD mapping reduces with the increase of accumulated strain in austenite. Although this is consistent with some research results, it contradicts other investigations showing grain coarsening after austenite deformation. This discrepancy can be related to differences in the transformation conditions and, thus, the transformed microstructures between these investigations. It was also found that active intragranular nucleation sites are important in achieving grain refinement.

\section{ACKNOWLEDGMENTS}

The authors thank Companhia Brasileira de Metalurgia e Mineração (CBMM) and the China Scholarship Council (CSC) for their financial support of this research program. Open access funding provided by The University of Sheffield. 


\section{OPEN ACCESS}

This article is distributed under the terms of the Creative Commons Attribution 4.0 International License (http://creativecommons.org/licenses/by/4.0/), which permits unrestricted use, distribution, and reproduction in any medium, provided you give appropriate credit to the original author(s) and the source, provide a link to the Creative Commons license, and indicate if changes were made.

\section{REFERENCES}

1. E.J. Palmiere, C.I. Garcia, and A.J. DeArdo: Metall. Mater. Trans. A, 1996, vol. 27A, pp. 951-60.

2. T. Kvackaj and I. Mamuzic: ISIJ Int., 1998, vol. 38, pp. 1270-76.

3. R. Zhang and J. Boyd: Metall. Mater. Trans. A, 2010, vol. 41A, pp. $1448-59$.

4. H.K.D.H. Bhadeshia: Bainite in Steels, Institute of Materials, London, 1992.

5. A.J. Deardo: Can. Metall. Q., 1988, vol. 27, pp. 141-54.

6. C. Ouchi: ISIJ Int., 2001, vol. 41, pp. 542-53.

7. M Umemoto, Z Hai Guo, and I Tamura: Mater. Sci. Technol., 1987, vol. 3, pp. 249-55.

8. Y Smith, A Coldren, and R Cryderman: Toward Improved Ductility and Toughness, Climax Molybdenum Development Co. Ltd., Kyoto, 1972.

9. Z. Tang and W. Stumpf: Mater. Charact., 2008, vol. 59, pp. $717-28$

10. Y.M. Kim, S.Y. Shin, H. Lee, B. Hwang, S. Lee, and N.J. Kim: Metall. Mater. Trans. A, 2007, vol. 38A, pp. 1731-42.

11. S. Lee, D. Kwon, Y.K. Lee, and O. Kwon: Metall. Mater. Trans. $A, 1995$, vol. 26A, pp. 1093-1100.

12. Y.M. Kim, H. Lee, and N.J. Kim: Mater. Sci. Eng. A, 2008 , vol. 478, pp. 361-70.

13. C. Shang, L. Hu, S. Yang, X. Wang, Y. Zhao, and X. He: Acta Metall. Sin., 2005, vol. 41, pp. 471-76.

14. N.Y. Zolotarevskii, A. Zisman, S. Panpurin, Y.F. Titovets, S. Golosienko, and E. Khlusova: Met. Sci. Heat Treat., 2014, vol. 55, pp. $550-58$.

15. H. Kawata, K. Sakamoto, T. Moritani, S. Morito, T. Furuhara, and T. Maki: Mater. Sci. Eng. A, 2006, vol. 438, pp. 140-44.

16. L. Malet, M. Barnett, P. Jacques, and S. Godet: Scripta Mater., 2009, vol. 61, pp. 520-23.

17. F.R. Xiao, B. Liao, Y.Y. Shan, G.Y. Qiao, Y. Zhong, C. Zhang, and K. Yang: Mater. Sci. Eng. A, 2006, vol. 431, pp. 41-52.

18. D. Bai, S. Yue, T. Maccagno, and J.J. Jonas: ISIJ Int., 1998, vol. 38 , pp. $371-79$.

19. K. Hulka and J.M. Gray: Proc. Int. Symp. Niobium, 2001, pp. $587-612$.

20. C. Miao, C. Shang, G. Zhang, and S. Subramanian: Mater. Sci. Eng. A, 2010, vol. 527, pp. 4985-92.

21. M.S. Mirza and C.M. Sellars: Mater. Sci. Technol., 2001, vol. 17, pp. 1133-41.

22. M.S. Mirza and C.M. Sellars: Mater. Sci. Technol., 2001, vol. 17, pp. $1142-48$.
23. M.S. Mirza and C.M. Sellars: Mater. Sci. Technol., 2007, vol. 23, pp. 567-76.

24. GF Vander Voort: Metallography, Principles and Practice, ASM International, Materials Park, OH, 1984.

25. D. Jorge-Badiola, A. Iza-Mendia, J.M. Rodriguez-Ibabe, and B. Lopez: ISIJ Int., 2010, vol. 50, pp. 546-55.

26. S. Hashimoto and M. Nakamura: ISIJ Int., 2006, vol. 46, pp. $1510-15$.

27. L. Sun, M.J. Thomas, B.P. Wynne, E.J. Palmiere, K.P. Mingard, and B. Roebuck: Mater. Sci. Technol., 2010, vol. 26, pp. 1477-86.

28. M.S. Loveday, G.J. Mahon, B. Roebuck, A.J. Lacey, E.J. Palmiere, C.M. Sellars, and M.R. Van der Winden: Mater. High Temp., 2006, vol. 23, pp. 85-118.

29. E.I. Poliak and J.J. Jonas: Acta Mater., 1996, vol. 44, pp. 127-36.

30. I. Yakubtsov and J. Boyd: Mater. Sci. Technol., 2001, vol. 17, pp. 296-301.

31. Y. Zhong, F. Xiao, J. Zhang, Y. Shan, W. Wang, and K. Yang: Acta Mater., 2006, vol. 54, pp. 435-43.

32. M.C. Zhao, K. Yang, F.R. Xiao, and Y.Y. Shan: Mater. Sci. Eng. $A$, 2003, vol. 355, pp. 126-36.

33. J.L. Lee, M.H. Hon, and G.H. Cheng: J. Mater. Sci., 1987, vol. 22 , pp. $2767-77$.

34. A.-F. Gourgues: Mater. Sci. Forum, 2003, vol. 426, pp. 3629-34.

35. H. Kitahara, R. Ueji, N. Tsuji, and Y. Minamino: Acta Mater., 2006, vol. 54, pp. 1279-88.

36. W. Wang, W. Yan, L. Zhu, P. Hu, Y. Shan, and K. Yang: Mater. Des., 2009, vol. 30, pp. 3436-43.

37. S. Kim, Y. Kim, Y. Lim, and N.J. Kim: Met. Mater. Int., 2006, vol. 12 , pp. 131-35.

38. P. Cizek, B.P. Wynne, C.H.J. Davies, and P.D. Hodgson: Metall. Mater. Trans. A, 2014, vol. 46A, pp. 407-25.

39. C. Roucoules, P. Hodgson, S. Yue, and J. Jonas: Metall. Mater. Trans. A, 1994, vol. 25A, pp. 389-400.

40. P. Uranga, A. Fernandez, B. Lopez, and J. Rodriguez-Ibabe: Mater. Sci. Eng. A, 2003, vol. 345, pp. 319-27.

41. G. Rees and H. Bhadeshia: Mater. Sci. Technol., 1994, vol. 10, pp. 353-58.

42. J.W. Brooks, M.H. Loretto, and R.E. Smallman: Acta Metall., 1979, vol. 27, pp. 1839-47.

43. W. Zhang, Y. Jin, and A. Khachaturyan: Acta Mater., 2007, vol. 55 , pp. $565-74$.

44. S. Yamamoto, H. Yokoyama, K. Yamada, and M. Niikura: ISIJ Int., 1995, vol. 35, pp. 1020-26.

45. J. Yang, C. Huang, and C. Chiou: ISIJ Int., 1995, vol. 35, pp. 1013-19.

46. C. Chiou, J. Yang, and C. Huang: Mater. Chem. Phys., 2001, vol. 69 , pp. 113-24.

47. K. Fujiwara, S. Okaguchi, and H. Ohtani: ISIJ Int., 1995, vol. 35, pp. $1006-12$

48. M. Olasolo, P. Uranga, J. Rodriguez-Ibabe, and B. López: Mater. Sci. Eng. A, 2011, vol. 528, pp. 2559-69.

49. H. Bhadeshia: Mater. Sci. Technol., 1999, vol. 15, pp. 22-29.

50. N. Takayama, G. Miyamoto, and T. Furuhara: Acta Mater., 2012, vol. 60 , pp. $2387-96$.

51. M Díaz-Fuentes and I Gutiérrez: Mater. Sci. Eng. A, 2003, vol. 363, pp. 316-24.

52. G Miyamoto, N Iwata, N Takayama, and T Furuhara: J. Alloy. Compd., 2012, vol. 577, pp. S528-32.

53. N. Isasti, D. Jorge-Badiola, M. Taheri, B. López, and P. Uranga: Metall. Mater. Trans. A, 2011, vol. 42A, pp. 3729-42. 